\title{
1st degree acromioclavicular sprain, elevated 1st rib, or both? A case study of a rodeo cowboy
}

\author{
Mark R. Lafave ${ }^{1,2}$, Dale J. Butterwick ${ }^{2,3}$, Blaine Bugg $^{2}$, Dave Roberts ${ }^{2}$ \\ ${ }^{1}$ Faculty of Health and Community Studies, Mount Royal University, Calgary, Canada; mlafave@mtroyal.ca \\ ${ }^{2}$ Canadian Professional Rodeo Sport Medicine Team, Calgary, Canada \\ ${ }^{3}$ Faculty of Kinesiology, University of Calgary, Calgary, Canada
}

Received 13 December 2013; revised 18 January 2014; accepted 25 January 2014

Copyright (C 2014 Mark R. Lafave et al. This is an open access article distributed under the Creative Commons Attribution License, which permits unrestricted use, distribution, and reproduction in any medium, provided the original work is properly cited. In accordance of the Creative Commons Attribution License all Copyrights (c) 2014 are reserved for SCIRP and the owner of the intellectual property Mark R. Lafave et al. All Copyright (C) 2014 are guarded by law and by SCIRP as a guardian.

\section{ABSTRACT}

Objective: To present a case of a rodeo cowboy who suffered a seemingly routine 1st degree acromioclavicular (AC) sprain. The AC sprain was exacerbated by an elevated 1st rib. Background: Saddle bronc riding is one of three rough stock events in North American rodeo and the least common event for injury relative to bull riding and bareback riding. Shoulder injury in rodeo rough stock events make up $9.3 \%$ of all injuries. Approximately $\mathbf{2 8 \%}$ of injuries in rodeo are considered minor sprains. The professional cowboy was thrown from his horse landing on the tip of his shoulder. The cowboy presented with a routine 1st degree AC sprain based on the Tossey and Rockwood definitions. Differential Diagnosis: Due to the mechanism of injury and forces produced with the cowboy being thrown to the ground, elimination of serious neck injury was critical. A scanning examination revealed some neck dysfunction. A cervical rotation, lateral flexion special test confirmed the additional elevated 1st rib in addition to the 1st degree AC sprain. Treatment: A chiropractic adjustment of the 1st rib reduced pain in the $A C$ joint from a $6 / 10$ to $1 / 10$ immediately. Subsequently, the patient iced and was treated with one other 1st rib adjustment at a later date. Uniqueness: There were no cases of 1st degree AC sprains with an associated elevated first rib in the literature. It was very unique to relieve to the patient's shoulder symptoms so dramatically in a short period of time with manual therapy to the first rib. Conclusions: It is important to follow a thorough history and physical examination of patients who suffer from a 1st degree AC sprain. The use of a scanning examination will help identify the primary source of pain (i.e. neck and/or shoulder). Manual therapy of the 1st rib may be useful in the treatment.

\section{KEYWORDS}

Manual Therapy; Chiropractic Adjustment; 1st Rib; AC Separation; Rodeo; Saddle Bronc; Shoulder Injury

\section{BACKGROUND}

Saddle bronc riding is a North American rodeo event whereby a competitor attempts to ride a bucking bronc (horse) for 8 seconds. The competitor uses a saddle and a single rope (halter shank) as part of the riding equipment. The harder the horse bucks, and the more aggressively and easily the rider performs, the more likely he will be judged as one of the best saddle bronc performers at that particular rodeo. The best competitors win money for their efforts. However, saddle bronc riding has associated risks. When cowboys are bucked off of the broncs they may be thrown very high in the air (over 15 feet) subsequently landing on a dirt arena (Figure 1). This combination can result in significant injury to the cowboy. Although fewer injuries occur during this event than the other two rough stock events (bull riding and bareback riding) it still has an injury rate of 17.5 for 1000 competitive exposures [1]. There are no specific data to identify shoulder injuries in the saddle bronc event, but in a fiveyear study there were $42 / 451$ (9.3\%) shoulder injuries across all events while 127/451 (28.2\%) minor sprains were recorded [1].

The Canadian Professional Rodeo Sport Medicine 


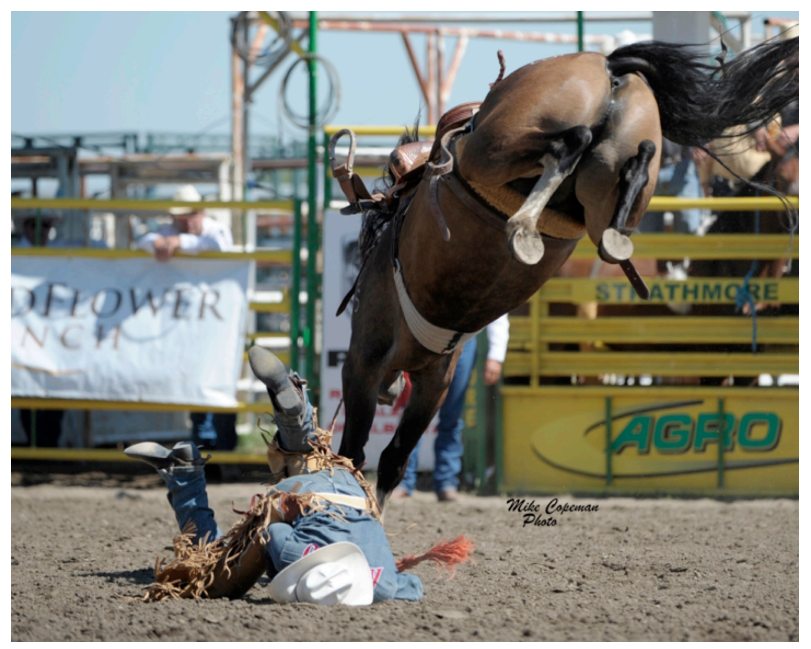

Figure 1. Mechanism of injury from an inappropriate, untimely dismount from saddle bronc horse.

Team (CPRSMT) is a group of volunteer athletic therapists (ATs), massage therapists and chiropractors (DCs) who work on site at 12 - 20 of the 60 rodeos in Canada per year. The onsite team works in a mobile treatment trailer and is fully equipped to manage acute and chronic injuries that present at any given rodeo. The CPRSMT triage system has new, acute injuries evaluated and managed by the AT. Other members of the team are consulted in challenging presentations or if the AT believes one of the other professionals can help provide immediate treatment for the athlete. Thus, the following case study is split into two segments related to the immediate evaluation and the inter-disciplinary treatment of a saddle bronc rider's shoulder injury.

\subsection{Clinical Presentation}

A 26-year-old professional saddle bronc rider was thrown from the saddle bronc. He landed on his neck and left shoulder based on the mechanism in Figure 1. Two athletic therapists went into the arena to evaluate the patient because he had remained down after his dismount. He said he initially felt winded, but caught his breadth and said he would be fine. The team checked for obvious deformity or the potential for other more serious neck injury prior to permitting him to get up and walk out of the arena. When outside the arena, the cowboy told the athletic therapist he was fine and would come back to the mobile treatment trailer at the end of the rodeo.

The cowboy/patient did come into the treatment trailer about one hour later. He asked an athletic therapist to evaluate his shoulder. The patient had no previous shoulder injuries. He complained of pain at the tip of his shoulder and pointed to the acromioclavicular (AC) joint. He did not complain of any other pain. However, when asked about neck pain or tingling or numbness into his hand, he said he felt a jolt of pain shooting around his "pinky" when he hit the ground. He denied any remarkable findings after the initial jolt. He subsequently denied any neck pain and was primarily focused on his shoulder.

\subsection{Physical Examination}

An initial scanning examination based on Magee's definition was performed whereby neck range of motion was tested [2]. He presented with stiffness on neck rotation and side bending, but no limited range of motion was noted. He had no referred pain when testing his neck range of motion. Thus, the neck was put aside for a brief time until a full shoulder examination was complete. Visual inspection did not reveal step deformity commonly associated with AC joint sprains. There did not appear to be any other deformities in the neck or shoulder.

Active shoulder range of motion was full in all directions, but painful at the end range with: flexion; horizontal flexion/adduction; and abduction. He did not complain of a painful arc (middle range of abduction). Passive range of motion testing resulted in the same motions being sore at the end ranges. Isometric strength testing was performed and all isometric positions were equally strong to the contralateral side except horizontal flexion/adduction. He had slight pain, but no weakness on shoulder/scapular elevation. All special testing was negative except the AC Shear test and caudad joint play of the clavicle described in Magee [2]. Palpation revealed point tenderness directly over the AC joint (i.e. 6/10), some mild tenderness over his upper trapezius and into his neck, but nowhere else around the shoulder, clavicle or scapula.

\section{INITIAL IMPRESSION}

The patient seemed to present with a first-degree AC joint sprain as classified by both the Tossy and Rockwood definitions $[3,4]$. There was no step deformity, no excessive joint play in the AC joint, it was only painful with palpation and extreme motions. However, there was the issue of the neck pain that remained unanswered.

It was suspected that the first rib might be elevated in addition to the AC injury due to the mechanism of injury (Figure 1), the transient shooting pain into his hand, and the scanning examination results (i.e. sore on some active neck movement). Posterior to anterior and cephalad to cauda rib springing was performed to test the mobility of the first and second ribs [2]. The 1st and 2nd rib were hypomobile and painful upon testing. Central vertebral pressure throughout the cervical and top six thoracic vertebral revealed no other significant neck injury or dysfunction. The cervical rotation, lateral flexion test was performed and was positive [5-7]. Palpation of the 
soft tissue around the neck and into the shoulder only revealed mild tenderness around the upper trapezius, rhomboids and levator scapulae muscles. An elevated first rib had been added to the final diagnosis. The DC was asked to confirm the diagnosis of an elevated first rib and he agreed.

\section{Treatment and Prognosis}

It should be noted that the cowboy patient population is often transient moving from one rodeo to another. These athletes live in isolated regions of the province/ country. Therefore, immediate treatment of the condition was considered without an X-ray or further diagnostic testing based on this patient's clinical presentation. The DC treated the cowboy's first rib with a thrust maneuver described in detail by Byfield [8]. The patient rose from the treatment table and was re-evaluated. His neck range of motion was full and pain-free. He did not have a positive cervical rotation, lateral flexion test any longer. When his AC joint was palpated again, he went from an initial 6/10 pain scale prior to the treatment of the first rib to a $1 / 10$. His range of motion in the shoulder was full and the pain at the full range of motion with abduction flexion almost disappeared. He still had minor pain (1 2/10) with horizontal flexion/adduction. The patient was given a bag of ice for his AC joint, told to keep the ice on for 20 minutes and repeat that treatment for the next 24 48 hours. He was told to follow up with our team by phone or one week later when he saw our team at the next rodeo. Again, the independent and transient nature of cowboys is such that he did not follow those instructions. He did, however, go to his local DC one other time for an adjustment to his rib. He continued to ride and perform very well for the rest of the season with minimal restrictions or pain.

\section{DISCUSSION}

The treatment setting, sport and injury in this case were all unique factors to consider. In a traditional clinical practice, an X-ray may have been completed to rule out other injuries. However, based on the circumstances and clinical presentation of this case, it was felt there was reasonable risk to treat this condition immediately.

To the best of our knowledge, there are no cases of a 1st degree AC joint sprain with an accompanying an elevated 1st rib in the literature. However, it should be noted that the CPRSMT have been exposed to a number these types of cases described above over the past 15 years. Other practitioners may consider a coupled injury/ diagnosis such the one presented in this paper in future shoulder evaluations. Moreover, the AC separation may be considered a differential diagnosis to the elevated first rib injury, or vice-versa. It appeared, based on the me- chanism of injury (Figure 1) that this patient suffered a significant force from the superior and lateral aspect of the shoulder. Therefore, we would suggest future evaluation of these types of injuries get a clear and detailed mechanism of injury as part of the history taking.

It is postulated that the first rib is vulnerable to elevation with this type of force or mechanism because it does not have a strong superior (cephalad) ligament at its costovertebral junction [7]. Furthermore, when the rib is in an elevated position, it is thought to cause an irritation of the C8 and T1 nerve roots, thus leading to radicular pain in that dermatome [7]. In the current case, the neurological symptoms were only transient, but it is possible that they may have persisted if the underlying cause of the elevated first rib was not managed properly.

When a coupled AC joint sprain-elevated first rib injury, complementary manual therapy treatment options could be considered. Despite the fact there were no cases specifically linking these two injuries together in the literature, there may been some evidence of this type of injury in the literature based on lingering symptoms and/ or complications from first degree AC joint sprains. For example, Johansen et al. [9] presented data collectively from a number of studies where patients with 1st and 2nd degree AC joint sprains continued to suffer from minor or major symptoms between 6 months and 10 years after their initial injury (Table 1). It may be that some of these patients also suffered from an elevated first rib that continued to cause trouble? Only future research would actually answer that question.

In an inter-disciplinary team environment, DCs are excellent at adjusting ribs and based on the results of this case, quite effective as well. Alternatively, when the AT is working in isolation, it is also possible for them to mobilize the first rib as is described by Lindgren \& Leino [7] or Lee and Walsh (Figure 2) [10]. A grade V manipulation was used in the current case, but a grade III or IV mobilization may also work as an alternative [10].

\section{CONCLUSION}

First-degree AC sprains are common in sport. It is important that a thorough history and physical examination

Table 1. A retrospective analysis of various studies with complications from AC sprains.

\begin{tabular}{cccc}
\hline & & Patients with Symptoms \\
\hline Authors & $\begin{array}{c}\text { Length of } \\
\text { Follow-Up }\end{array}$ & Minor (\%) & Major (\%) \\
\hline Bergfeld et al., 1978 & 6-42 Mos & 30 & 9 \\
Cox, 1981 & $6-60$ Mos & 28 & 8 \\
Mouhsine et al., 2003 & $6.3 \mathrm{Yr}$ & - & 19 \\
Mikek, 2008 & $10.2 \mathrm{Yr}$ & 52 & -
\end{tabular}






Figure 2. Hand position for mobilization of the first rib. The right hand is considered the treating hand with oscillations moving in a cephalad to caudad direction.

occurs to accurately diagnose the injury. A scanning examination whereby the therapist ensures the symptoms are actually in the site of injury (i.e. shoulder in this case) is an important aspect of being thorough. The scanning examination in this case study revealed involvement of the neck and first rib. Treatment of the elevated first rib almost entirely removed the pain in the AC joint immediately. To our knowledge, this is the first case presentation to combine a 1st degree AC sprain with an elevated 1st rib. Future shoulder evaluation may consider this coupled injury as a differential diagnosis.

\section{ACKNOWLEDGEMENTS}

We would like to acknowledge the support of the Canadian Professional Rodeo Association, the Canadian Professional Rodeo Sport Medicine Team and photographer, Mike Copeman.

\section{REFERENCES}

[1] Butterwick, D.J., Hagel, B.E., Nelson, D.S., Lafave, M.R. and Meeuwisse, W.H. (2002) Epidemiological analysis of injury in five years of canadian professional rodeo. The American Journal of Sports Medicine, 30, 193-198.

[2] Magee, D. (2008) Orthopedic physical assessment. 5th Edition, Saunders, Toronto.

[3] Tossy, J., Mead, N. and Sigmond, H. (1963) Acromioclavicular separation: Useful and practical classification for treatment. Clinical Orthopaedics \& Related Research, 28, 111-119.

[4] Rockwood, C. and Green, D. (1984) Fractures in adults. 2nd Edition, Lippincott, Philadelphia.

[5] Lindgren, K., Leino, E. and Manninen, H. (1992) Cervical rotation lateral flexion test in brachialgia. Archives of Physical Medicine and Rehabilitation, 73, 735-737.

[6] Lindgren, K., Leino, E., Hakola, M. and Hamberg, J. (1990) Cervical spine rotation and lateral flexion combined motion in the examination of thoracic outlet. Archives of Physical Medicine and Rehabilitation, 71, 343-344.

[7] Lindgren, K. and Leino, E. (1988) Subluxation of the first rib: A possible thoracic outlet syndrome mechanism. Archives of Physical Medicine and Rehabilitation, 68, 692695.

[8] Byfield, D. (2001) Chiropractic manipulative skills. Reed Educational and Professional Publishing Ltd., Oxford, 256-290.

[9] Johansen, J., Grutter, P., McFarland, E. and Petersen, S. (2011) Acromioclavicular joint injuries: Indications for treatment and treatment options. Journal of Shoulder and Elbow Surgery, 20, S70-S82. http://dx.doi.org/10.1016/j.jse.2010.10.030

[10] Lee, D. and Walsh, M. (1996) Workbook of manual therapy techniques for the vertebral column and pelvic girdle. Friesen Printers, Manitoba. 